\title{
SALÕES DE CULTOS E BANQUETES: A COMPREENSÃO DOS ESPAÇOS ESCANDINAVOS
}

Munir Lutfe Ayoub*

RESUMO: 0 presente artigo tem como maior objetivo entender as atribuições e compreensões vinculadas com os salões, edifícios que ganhavam maior destaque na formação dos espaços religiosos e políticos da Escandinávia no período viking, possibilitando o entendimento das formações espaciais de convívio social, denominadas cidades e centros políticos e religiosos.

PALAVRAS-CHAVE: Salões; Vikings; Espaço.

ABSTRACT: This paper has as main objective to understand the roles and comprehensions linked with the Halls, who earned most outstanding buildings in the formation of religious and political spaces in Scandinavia during Viking age, comprehensions that will enable the understanding of spatial formations of social interaction, called cities and political and religious centers.

KEYWORDS: Hall; Viking; Space.

(recebido em 11/01/2013, aprovado em 19/05/2013)

Os vikings são lembrados, pelo imaginário popular e pelas antigas produções românticas e nacionalistas, como invasores que destruíram e espalharam pavor por toda a Europa. Por essa compreensão, o período foi datado como tendo início no ano de 793, quando ocorreu o ataque nórdico à Inglaterra, mais precisamente na região de Lindisfarne. Contudo, a historiografia atual tem se esforçado para uma maior percepção desses povos $^{1}$ e de suas sociedades, tentando compreende-los com outros olhares².

Podemos começar com a desconstrução da compreensão do período viking do século XIX e do início do século XX, analisando-se o próprio termo "viking". Esse vocábulo, que durante a Idade Média

* Mestrando PUC-SP. E-mail: munirlutfe@gmail.com. Membro do grupo Neve (Núcleo de estudos vikings e escandinavos)

1 Durante o período Viking a Dinamarca se encontrava habitada pelos povos daneses, a Suécia se encontrava dividida pelos povos Svears e Gotars e a Noruega se dividida entre inúmeras pequenas povoações que habitavam seus fiordes.

2 RICHARDS, Julian D. Vikings. A very short introduction. New York: Oxford University Press, 2005, p. 2-7.

SAWYER, Peter. The Oxford illustrated History of the Vikings. New York: Oxford University Press, 2001, p. 49-50.

ROESDAHL, Else. The Vikings. Tradução de Susan M. Margeson; Kirsten Williams. London: Penguin Books, 1998, p. 9-11.

GRIFFITH, Paddy. Los Vikingos el terror de Europa. Tradução de Mateus Albert Sasot. Barcelona: Ariel, 2004, p. 13-46. 
tinha um caráter plural, foi citado pela primeira vez nas Crônicas anglo-saxônicas, referindo-se a atividades de saques e pirataria. No entanto, o termo passa a se demonstrar múltiplo, na medida em que encontramos sua utilização nas fontes escritas em Old Norse, a língua dos habitantes da Escandinávia no período viking, nas quais o vocábulo adquire muitas formas. Por exemplo, na Knutsdrapa, as tropas de Cnut são lembradas como Víkingar; nesse caso, está ressaltando a ferocidade destes homens. Portanto, podemos dizer que a expressão viking não está necessariamente vinculada a atividades consideradas bárbaras, como os ataques de saques e pirataria. Contudo, quando nasceu a compreensão moderna do termo viking?

A origem da atual utilização da terminologia viking foi muito discutida pelos historiadores, e Julian D. Richards sintetiza essas inúmeras discussões em seu trabalho:

The actual derivation of the term viking has been much debated. It has been suggested that both the Old English and Old Norse forms are parallel developments from a common Germanic verb meaning 'to withdraw, leave or depart'; that it is related to the Old Icelandic vik, meaning a bay or creek; that it refers to those from the area of Vik or Viken around the Oslofjord who embarked on the raiding of England to escape Danish hegemony; that it derives from vika, a turn on duty, or relay oarsmen; that it derives from an Old Icelandic verb vikya, meaning 'to turn aside', or the Old English wic, or armed camp ${ }^{3}$.

Pela descrição do historiador Julian D. Richards começamos a perceber que é a compreensão moderna do termo e do período Viking que acabou por ligar exclusivamente esses povos a momentos de invasão e de saques, além de vinculá-los à ideia de bárbaros ferozes que atacavam as igrejas no período medieval, saqueavam as mais diversas localidades da Europa, matavam muitos clérigos, sendo até mesmo considerados como verdadeiros demônios na terra.

Contudo tais povos têm de passar a ser entendidos como pertencentes a seu tempo. Devemos entendê-los não mais como selvagens guerreiros, porém como famílias com suas fazendas, vivendo em sociedade, envolvendo-se em disputas de poder e que, sobretudo, partilhavam de uma cultura, uma linguagem, uma religião e um entendimento de mundo muito voltado para a guerra, que por sua vez os

RICHARDS, op. Citi. , 2005, p. 4.

"A atual derivação do termo viking tem sido muito debatida. Tem sido sugerido que tanto a forma em ingles antigo quanto em nordico antigo são evoluções paralelas de um verbo germanico que significa 'retirar-se, deixar ou partir'; verbo que se relaciona com o islandes antigos vik, palavra que significa baía ou enseada; que se refere a região de Vik ou Viken em torno de Oslofjord onde embarcaram os invasores da Inglaterra para escamparem da hegemonia Danesa; que deriva de vika, um turno de trabalho, ou uma equipe de remadores; que deriva do verbo vikya que em islandes antigo significa 'se voltar para fora', ou em ingles antigo wic, campo armado." (Tradução livre do autor). 
fazia adotar tais valores. A desmistificação da imagem dos vikings foi demonstrada pelo historiador Paddy Griffith:

La mayoría de ellos eran poco más que <<civiles con un elevado grado de concienciación sobre temas de seguridad $\gg$, individuos preocupados por el riesgo de agresión presente en la gestión de sus transacciones habituales. Para un vikingo, un <<soldado >> equivalía, acaso, a <<ciudadano ordinario que comprende que vive en un entorno humano peligroso > $>$. Alguien que necesitaba asegurar su protección personal y que dominaba una fuerza que podía llegar a ser letal si las circunstancias lo requerían, aunque sin dejar de ser por ello un $<<h o m b r e ~ p a r a ~ t o d o \gg>$, un navegante, un marido o un atleta ${ }^{4}$.

Podemos dizer, portanto, que os escandinavos durante a alta Idade Média não se identificavam como Vikings, na verdade eles se identificavam pela nomenclatura de suas regiões: homens de Jutland, Vestfold, Horland e de tantas outras localidades. A historiografia moderna, ao buscar a desmistificação desses povos, iniciou outra observação sobre esse período, pautada em perguntas como: 0 que marcou o início do período viking? O período viking tem de ser observado por quais modificações sociais?

O período viking tem como sua principal marca uma forte expansão marítima, quando os escandinavos praticavam uma série de excursões com o objetivo de saque, pilhagem, comércio ou até mesmo com o intuito de habitarem regiões que hoje conhecemos como Inglaterra, Escócia, Irlanda, Islândia, Shetland, Orkney e até mesmo Rússia, Finlândia e o norte da América ${ }^{5}$. Contudo, não podemos nos esquecer de que o desenvolvimento de cidades, o surgimento ou a continuidade de centros religiosos e políticos, o início da centralização da autoridade, o início das atividades comerciais e 0 aumento da produção de bens como jóias, armas e tantos outros produtos também marcaram 0

4 GRIFFITH, Paddy. Los Vikingos el terror de Europa. Tradução de Mateus Albert Sasot. Barcelona: Ariel, 2004, p. 26.

"A maioria deles eram pouco mais que <<civis com um elevado grau de consciência sobre temas de segurança〉>, indivíduos preocupados pelos riscos de agressão presentes na execução de suas atividades habituais. Para um viking, um «soldado»> equivalia, talvez, a um « cidadão comum que compreendia que vivia em um entorno humano perigoso >. Alguém que necessitava garantir sua proteção pessoal e que detinha uma força que podia chegar a ser letal se as circunstancias exigissem, embora sem deixar de ser por isso um «<homem completo >>, um navegante, um marido ou um atleta" (Tradução livre do autor). 
início desse período 6 . A partir dessa compreensão nosso trabalho tem o intuito de analisar os edifícios que se encontravam em posição de destaque em cidades e centros religiosos e políticos, como os suecos Uppsala, Adelsö, Birka e Fornsigtuna buscando compreender a função e importância dessas construções na organização cosmológica dos centros escandinavos do período Viking.

Serão estudados os edifícios que habitualmente se encontravam nos locais mais altos e eram as maiores construções dessas cidades, ganhando assim uma localização de destaque em relação às demais construções do período. Em Upssalana, ao norte da igreja situada em Kungsgarden, dois platôs de argila foram construídos; o platô do sul tem 2,5 metros de altura e nele se situava o salão durante 0 período de Vendel, antecessor ao período viking. Em Adelsö, o terraço de Hovgarden tem entre 1 e 2 metros de altura e se situa no extremo do istmo de Mälaren. Em Birka, o maior dos salões suecos se situa exposto em um terraço de fácil visualização, separado do resto da cidade. Em Garisson, o salão pode ser facilmente observado desde a longínqua ilha de Björkö; durante o período viking era um importante local de comércio. Por último, a cidade de Fornsigtuna tem seu salão situado em seu platô principal, exposto em um promontório, ao lado do canal da baía de Hatuna. Contudo, não eram apenas as localizações dos salões que lhes davam um grande destaque. Suas arquiteturas nos demonstram a expressão de grandeza e de luxo de uma aristocracia escandinava. Na antiga Uppsala, o salão situado em seu platô ao sul media $40 \mathrm{~m}$ de comprimento por $12 \mathrm{~m}$ de largura, estando seus postes, com 50-90 cm de diâmetro, enterrados a 1,47 m abaixo da terra. A arquitetura demonstra, assim, um grande salão, que provavelmente possuiria mais de um andar, realçando sua grandeza ao lado das outras construções do período, além de estar localizado com grande visibilidade e altura ${ }^{7}$. Nosso trabalho pretende compreender, portanto, a função desses salões e as características que eles atribuíam às cidades ou aos centros políticos e religiosos escandinavos.

\section{Culto e festividades: a construção do espaço civil}

Os salões apresentados em nosso trabalho eram interpretados, por volta do século XIX e da primeira metade do século $X X$, como locais de cultos religiosos, verdadeiros templos pagãos,

\footnotetext{
6 SKRE, Dagfinn. The development of urbanism in Scandinavia. In: PRICE, Neil. (Org.). The Viking World. New York: Routledge, 2007. p. 83-92.

7 SUNDQVIST, Olof. An Arena for Higher Powers. Cult Buildings and Rulers in the Late Iron Age and The Early Medieval Period in The Mälar Region. In: Ideology and power in the Viking and Middle Ages Scandinavia, Iceland, Ireland, Orkney and the Faeroes. (Orgs.) STEINSLAND, Gro. Boston: Leiden, 2011. p. 187-188.
} 
compreensão que derivava da crença nas fontes que relatam o período escandinavo pré-cristão como fiéis ao ocorrido, ou até mesmo em traduções equivocadas de obras tradicionais, como a Gesta Hammaburgensis Ecclesiae Pontificum. Entre essas fontes se encontram compilações de homens como o islandês Snorri Sturluson e o germano Adam de Bremen:

That folk (the Swedes) has a very famous temple called Uppsala, situated not far from the city of Sigtuna and Björkö. In this temple, entirely decked out in gold, the people worship the statues of three gods $[\ldots]^{8}$

Sigurd the Earl of Lade was very fond of offering up sacrifices, as was Hakon, his father, before him. Sigurd always presided, on the king's behalf, over sacrificial feasts in the Trondelag (the district around Trondeheim). When there was to be a sacrifice, it used to be the custom that all the landowners would bring with them to the temple whatever food they would need during the festivities ${ }^{9}$.

Era essa religiosidade e sua compreensão que atribuíam à realeza escandinava um caráter sacro, responsável pela execução dos cultos praticados nesses edifícios, além de explicar componentes e atributos que formavam esses salões. Assim, objetos encontrados em escavações, por exemplo, as plaquetas de ouro, eram compreendidos por historiadores e arqueólogos como Torun Zachrisson e Lotte Hedeager como objetos ritualísticos, depositados com a intenção de atribuir honra, respeito e um caráter sacro a esses reis, às suas linhagens e a esses salões, uma vez que se encontram depositadas em baixo deles ${ }^{10}$. Tais depósitos e salões eram geralmente protegidos por

8 BREMEM, Adam of. Gesta Hammaburgensis Ecclesiae Pontificum. Tradução de F.J. Tschan. New York: Columbia University Press, 2002, p.207-208.

"Aquele povo (os suecos) tem um templo muito famoso chamado Uppsala, situado perto das cidades de Sigtuna e Björkö. Naquele templo, totalmente decorado em ouro, as pessoas cultuam a estatua de três deuses" (Tradução livre do autor).

STURLUSON, Snorri. Hákonar Saga góda. In: Heimskringla. Tradução de N. Linder og H.A. Haggson. Disponível em: <http://www.heimskringla.no/wiki/Saga_Hákonar_góða>. Acesso em: 08 ago. 2012.

"Sigurd o chefe local de Lade tinha um grande prazer de oferecer sacrifícios assim como Hakon, seu pai, fez antes dele. Sigurd sempre presidia, ao lado do rei, as festas sacrificais em Trondelag (o distrito ao redor de Trondeheim). Quando estava para ocorrer um sacrifício existia-se o costume, no qual todos os proprietários de terras traziam com eles ao templo os alimentos que precisariam durante as festividades" (Tradução livre do autor).

Os resquícios das primeiras edificações que contavam com depósitos de objetos em suas fundações datam para 0 século I a.C. esses depósitos eram compostos por pedaços de cerâmica, ossos de animais, pederneiras, grãos, ferramentas de trabalho e alguns objetos de ferro e bronze. Contudo durante o século VI d.C. até o final do período Viking essa composição passaria a se alterar no contexto de algumas edificações especificas, diferenciando-se do restante ao passarem a incluir em seus depósitos objetos de grande luxo como moedas, plaquetas de ouro, armas e 
espíritos conectados a essas linhagens, como cães, dragões e outros animais, os quais tinham por objetivo atribuir características guerreiras, mágicas e de fertilidade aos aristocratas ${ }^{11}$. Por último, podemos ver Odin como sendo o deus que segundo a Ynglinga saga tinha o conhecimento de todos esses depósitos, que os protegia e que podia retirá-los da terra utilizando magias como 0 Galdr, dando ao deus caolho a responsabilidade de zelar ou até mesmo de destruir uma linhagem real12.

Outros atributos desses salões que lhes dava uma compreensão cósmica e religiosa eram as suas estacas de sustentação, muitas vezes apresentadas em obras literárias como verdadeiras árvores. Vale nos lembrarmos de compilações como a Volsunga Saga, compreendida como parte formadora de Yggdrasil, as quais davam a esses edifícios um caráter de pertencimento ao axis-mundi que conectaria essas sociedades ao mundo sobrenatural e que explicaria os depósitos que ocorriam junto a essas estacas ${ }^{13}$. Por essas inúmeras compreensões, eram cidades como Gudme e Uppsala consideradas como locais ritualísticos, que tiveram suas primeiras formações justificadas pelos seus componentes centrais para a religiosidade nórdica, cidades que ganhavam, na análise de historiadores, o caráter de centros religiosos das práticas pré-cristãs escandinavas. Ao considerarmos as toponímias dessas regiões, percebemos em Gudme o aspecto religioso ressaltado pela tradução do seu nome,

utensílios domésticos como taças de vidro e de metal.

Os objetos de luxo e de ouro encontrados nesses edifícios levam a compreensão de um contexto ritual, uma vez que 0 ouro se torna um metal de grande importância ritualística em contexto escandinavo desde 0 século $\mathrm{V}$ d.C., por dentre outras coisas serem encontradas em diversos salões sempre junto as estacas de sustentação do teto e perto das paredes e entradas demarcando uma atitude regular que respeitava a variante espaço temporal.

HEDEAGER, Lotte. Iron Age Myth and Materiality: An Archaeology of Scandinavia ad 400-1000. New York: Routledge, 2011, p. 172-173.

STEINSLAND, Gro. Det hellige bryllup og norron kongeideologi. En analyse av hierogami-myten i Skírnismál, Ynglingatal, Háleygjatal og Hyndluljód. Oslo: Solum, 1991.

SUNDQVIST, Olof. Freyr's offspring: Rulers and religion in ancient Svea society. Uppsala: Uppsala Universitet, 2002.

ZACHRISSON, T. Gard, Gräns, Gravfält. Sammanhang kring ädelmetalldepaer och runstenar fran vikingetid och tidigmedeltid in Uppland och Gästrikland. Stockholm Studies in Archaeology, n. 15, p. 62-134, 1998.

STURLUSON, Snorri. Odin's Lawgiving. In: Ynglinga Saga. Tradução de Samuel Laing. Disponivel em: <http://omacl.org/Heimskringla/ynglinga.html>. Acesso em: 08 ago. 2012.

OBRA ANÔNIMA. Sagas islandesas: Saga dos Volsungos. Tradução e edição de Théo de Borba Moosburger. São Paulo: Hedra, 2009, p. 41-42.

RAUDVERE, Catharina. Myth, genealogy, and narration: some motifs in Volsunga Saga from the perspective of the History of Religions. In: Reflections on Old Norse myths. (orgs.) HERMANN, Pernille; SCHJODT, Jens Peter; KRISTENSEN, Rasmus Tranum. Turnhout: Brepols Publishers n.v., 2007. p. 119-132. 
muitas vezes compreendido como a casa dos deuses, e também em Uppsala, em que o sufixo sal, que poderíamos traduzir como salão, evidencia a importância desse edifício para a construção dessas espacialidades ${ }^{14 .}$

No entanto, a partir da segunda metade do século $X X$, as fontes estrangeiras e as sagas escritas por escandinavos começaram a ganhar muitas críticas e reavaliações das suas ideias e sobre a sua datação, estando historiadores e arqueólogos como Olaf Olsen na vanguarda dessas novas perspectivas. As fontes, então, passaram a não ser mais atribuídas a relatos fiéis da antiga religiosidade nórdica. As sagas sofreram criticas pelos seus períodos de datação, já cristão, sendo essas compilações produzidas em época muito posterior ao fim dessas práticas e edifícios. Portanto, por mais que tenham sido escritas por escandinavos, as perspectivas religiosas e cósmicas já se encontravam diferenciadas.

Os relatos de estrangeiros como Adam de Bremen foram escritos em períodos de prática da antiga fé nórdica, no entanto, seus escritos carregam compreensões que não eram próprias nem das regiões e nem dos costumes dos povos escandinavos. Sendo assim, passou-se a acreditar nesses templos como construções de períodos e mentalidades habituados a religiosidade e costumes diferentes daqueles praticados pelos escandinavos pré-cristãos, lançando os estudos a uma nova perspectiva e a uma nova pergunta: Quais eram as outras utilizações desses salões?

Segundo historiadores como Ciro Flamarion Cardoso e a historiadora e arqueóloga Juliand D. Richards, os escandinavos que praticavam a antiga fé nórdica tinham uma noção mais fluida dos limites e contatos desse mundo e dos outros, sendo que os cultos não necessariamente eram praticados em locais de uso exclusivamente religioso ${ }^{15}$. Salões como o de Hofstathir, na Islândia,

14 HEDEAGER, op. Citi. , 2011, p. 158-173.

ABRAM, Christopher. Myths of the Pagan North. Auckland: Continuum International Publishing Group, 2011, p. 913-986.

BRINK, Stefan. Naming the Land. In: The Viking World. (Org.) PRICE, Neil. New York: Routledge, 2007. p. 57-65.

15 ABRAM, Christopher. Myths of the Pagan North. Auckland: Continuum International Publishing Group, 2011, p. 10531058.

CARDOSO, Ciro Flamarion. A interpretação da cosmogonia religiosa com a história entre os escandinavos. Rio de Janeiro: Revista Eletrônica de Antiguidade, n. 9, p. 8-19, 2012.

DAVIDSON, H.R. Ellis. The lost beliefs of Northern Europe. London: Routledge, 2003, p. 23-24.

HERSCHEND, Frands. The idea of the Good in Late Iron Age Society. Uppsala: Uppsala Universitet, 1998, p. 182. HERSCHEND, Frands. The idea of the Good in Late Iron Age Society. Uppsala: Uppsala Universitet, 1998, p. 182. HERSCHEND, Frands. origin of the Hall in Southern Scandinavia. Tor, n. 25, p. 175-199, 1993.

HULTGARD, Anders. The religion of the Vikings. In: The Viking World. (Orgs.) BRINK, Stefan; PRICE, Neil. London: Routledge, 2007. p. 212-674.

HUTTON, Ronald. The pagan religions of the ancient British isles: their nature and legacy. Oxford (UK); Cambridge (Mass): Blackwell, 1995, p. 270-271. 
ajudaram nessa compreensão. Tal salão tinha 36 metros de comprimento e uma largura de 6 a 8 metros. Em seu interior havia uma lareira, no centro, bancos ao longo das paredes e uma pequena lareira ao norte. Ali foram achados ossos de bois e de carneiros, que possivelmente teriam sido sacrificados, preparados e cozidos em um pântano próximo ao salão. $O$ formato do salão com suas fogueiras e longos bancos refletem a descrição já apresentada dos locais de culto, além da presença de ossos animais poder sugerir uma utilização sacrifical. Porém, interpretações como as do historiador Ciro Flamarion e de Jean Renaud sugerem a realização de banquetes não exclusivamente de sacrifício, uma vez que as escavações arqueológicas demonstram entre os depósitos de objetos de luxo outros depósitos de caráter não ritualístico como o deposito de armas.

O aspecto guerreiro dos povos nórdicos e os depósitos de armas que ocorriam nos salões podem ter influenciado a descrição de salões como o Valhalla, salão do deus Odin, onde armas e escudos fazem parte de sua decoração, denotando não apenas uma utilização religiosa, mas também guerreira, atribuindo a esses salões uma multiplicidade que cercava as festividades e banquetes entre guerreiros, reis e chefes locais ${ }^{16}$.

Atualmente, historiadores como Olof Sundqvist seguem a linha de pensamento de um salão múltiplo, não conectado apenas com a religião. No entanto, demonstra-se que fontes escritas em um período medieval estariam na verdade a indicar essa multiplicidade e que as traduções, feitas no fim do século XIX e do início do XX, ao se equivocarem, acabaram por prejudicar essa interpretação. Assim, necessitamos de um contato direto com fontes como a escrita por Adam de Bremen, Gesta Hammaburgensis Ecclesiae Pontificum, na qual foi possível observarmos três termos diferentes usados pelo escritor ao designar os salões nórdicos. São esses termos templo, templum e triclinium, sendo os dois primeiros traduzidos como templo e o terceiro adquirindo no latim uma compreensão mais múltipla, conectada aos grandes salões, onde ocorreriam banquetes de diversas formas e com diversos motivos, até mesmo para uma comemoração de vitórias em guerra ou de boas colheitas ${ }^{17}$.

LINDOW, John. Norse mythology: a guide to the gods, heroes, rituals and beliefs. New York: Oxford University Press, 2002, p. 34.

RENAUD, Jean. Les dieux des Vikings. Rennes: Éditions Quest-France, 1996, p. 161-162.

RICHARDS, op. Citi. , 2005, p. 20.

SLUPECKI, Leszek P. Pagan temple - Christian Church. The Problem of Old Norse Temples. In: Between Paganism and Christianity in the North. (Orgs.) SLUPECKI, Leszek P.; MORAWIEC, Jakub. RzesZów: Wydawnictwo Uniwersytetu Rzeszowskiego, 2009. p. 23-44. SUNDQVIST, op. Citi., 2011. p. 163-210. 
Nobilissimum illa gens templum habet, quod Ubsola dicitur, non longe positum ab Sictona. In hoc templo, quod totum ex auro paratum est, statuas trium deorum veneratur populis, ita ut potentissimus eorum Thor in médio solium habeat triclinio; hinc et inde locum possident Wodan et Fricco ${ }^{18}$.

Para concluirmos a compreensão desses salões vale ressaltarmos que eles se diferenciavam dos demais edifícios de seus períodos por suas localidades, seus depósitos, suas arquiteturas e suas decorações, as quais Ihes davam certo destaque e certa grandeza. No entanto, tais atributos não tinham um caráter único de fé, mas sim também um caráter político e ideológico, conectado com os homens que utilizavam os salões e que pode ser percebido pelos objetos que adornavam suas paredes e portas. Contamos com numerosas descrições dos objetos que adornavam essas construções, entre elas encontramos os relatos sagas como Laxdæla Saga e Gretti's Saga, que nos demonstram e descrevem as paredes talhadas ou trabalhadas em metais, com representações de sagas e mitos lembrando os heróis, reis e deuses daqueles povos ${ }^{19}$.

Eram assim esses salões utilizados pela aristocracia para os momentos mais diversos como casamentos, banquetes e comemorações de vitórias em guerra. Aristocracia que tinha como uma de suas funções a proteção dessas cidades e desses centros religiosos e políticos, estabelecendo um controle da organização social e legislativa. Em um momento propenso de saques, como o período viking, devemos lembrar que eram esses aristocratas responsáveis, dentre outras coisas, por manter certa segurança espacial. Isso ocorria de forma a permitir que comerciantes viessem para suas terras e que nelas estabelecessem boas relações. Dessa maneira eles possibilitaram o florescimento do comércio, o enriquecimento dos comerciantes e dos próprios aristocratas que cobravam tributos e taxas. O salão era um símbolo de aristocracia que acabaria por caracterizar as cidades e centros escandinavos. Percebemos essas compreensões em poemas como Beowulf, o qual apresenta, em sua configuração, elementos de grandeza e beleza, tendo se tornado um símbolo do poder de um rei ou chefe local.

18 BREMEM, Adam of. Gesta Hammaburgensis Ecclesiae Pontificum. Ed. B. Schmeidler Hannover: Hannover and Leipzig, 1917, p. 78.

"Aquele povo tem um templo muito famoso chamado Uppsala, situado perto da cidade de Sigtuna. Naquele templo, totalmente decorado em ouro, as pessoas cultuam a estatua de três deuses de tal modo que o mais poderoso deles, Thor, ocupa o trono no meio do salão; Wotan e Frikko têm seus tronos ao lado." (Tradução livre do autor).

19 OBRA ANÔNIMA. Capitulo 29. In: The Laxdoela Saga. Tradução de Margaret Arent. Washington: University of Washington Press, 1964, p.86.

OBRA ANONIMA. Capitulo 15. In: Grettis saga Ásmundarsonar. Tradução de Richard C. Halle Boer. Altnordische Saga-Bibliothek 8, 1900, p.69. 
Then Hrotgar was given victory in battle,

Such honor in war that the men of his house

eagerly served him, while younger kinsmen

grew into strength. It came to his mind

that he would command a royal building,

a gabled mead-hall fashioned by craftsmen,

which the sons of men should hear of forever,

and there within he would share out

among young and old all God had given him,

except common land and the lives of men.

Then, I have heard, the work was announced

To many peoples throughout middle-earth,

That they should adorn this nation's hall.

In due time, yet quickly it came to be finished,

Greatest of hall-buildings. He, whose word

Had power everywhere, said its name, "Heorot"20.

Com tal destaque, os salões acabavam por ceder às suas cidades ou centros políticos e religiosos uma compreensão de local sagrado, aristocrático e seguro; um local defendido pela aristocracia e de caráter diferencial, ao ganhar leis próprias distintas do restante do território. A lei de Birka, chamada assim a partir do nome da primeira cidade sueca a utilizá-la, demonstra a diferenciação jurídica de tais localidades. As toponímias também nos indicam a importância dessas construções, já que muitas delas indicam a presença desses edifícios. Entre elas encontramos as que apresentam a palavra Sal e a palavra Hof, que significam salão e estão presentes, por exemplo, nos nomes de Uppsala e Hofstathir. Assim sendo, iniciava-se uma compreensão cósmica desses locais de relação social, que partia dos salões, abrangia as cidades, os centros políticos e os religiosos, acabando por opô-los às florestas, montanhas, mares, rios e pântanos, onde a lei era imprecisa e a terra era habitada por animais selvagens e homens proscritos ${ }^{21,22}$. A historiadora e arqueóloga Lotte Hedeager constrói e desenvolve essa compreensão da oposição entre cidades e áreas selvagens em sua obra Iron Age Myth and Materiality:

20 OBRA ANÔNIMA. Beowulf. Tradução e edição de Howell D. Chickering, Jr. New York: Anchor Books, 2006, p. 25.

"Então a vitória na Batalha foi dada a Hotgar,/ Tal honra na guerra fez com que os homens de sua casa/ Avidamente Ihe servissem, enquanto o jovem rei/ Crescia em força. Então Ihe veio em sua mente/ $\mathrm{A}$ ideia de comandar um edifício real,/ Um grande salão de hidromel feito por artesãos, I Que os filhos dos homens iriam ouvir para sempre, / E lá dentro o rei iria partilhar, / Entre jovens e velhos tudo o que deus Ihe tinha dado,/ Exceto a terra comum e a vida dos homens./ Então, eu ouvi, a construção foi anunciada/ Para muitos povos por toda a terra media,/ Que eles deveriam adornar o salão dessa nação./ No devido tempo, rapidamente esse veio a ficar pronto,

O maior dos salões. Aquele, cujo o nome/ Tinha poder em todos os lugares, deu-se o seu nome, "Heorot'." (Tradução livre do autor). 
The creation of sacred places in pre-Christian Scandinavia must have been embedded in Norse cosmology, of which, however, very little is know. In a society without any form of central public power, a precarious peace had to be constantly negotiated. Here the most important institutions were the home, the hall and the thing, where social and legal negotiations took place. According to the sagas, these institutions were the sacred foundations of society, the focal points in the topographical structure of the Icelandic universe in the Early Middle Ages. The most common locations for combat and open attack were outside the precinct of the farms (utangards): in woods, near rivers and in areas bordering on the wild interior, that is, the 'outside' dangerous world23.

\section{Considerações finais}

Enfim, compreendemos o mundo viking para além das imagens já populares de guerreiros, piratas e destruidores assolando a Europa durante a Alta Idade Média. Os escandinavos eram mais do que destruidores de cidades e de centros religiosos europeus, já que eles formavam em suas terras comunidades que partilhavam de uma religiosidade e de um sistema político muito próprio, e que tem despertado o interesse de numerosos historiadores nos estudos atuais sobre a Idade Média. Esse mundo, portanto, não pode mais ser rotulado ou simplesmente esquecido, como se fosse uma parte menor e excêntrica da formação ocidental da Europa. Os escandinavos têm de passar a ser entendidos como formadores de compreensões sociais, religiosas e culturais de um período que costumamos denominar de medieval. Seguindo tal entendimento, suas organizações territoriais são de suma importância na compreensão desse mundo, uma vez que toda a cosmovisão e toda a criação espacial têm em seu cerne aspectos da mentalidade e da sociabilidade de um determinado povo, visto que 0 espaço é organizado não por uma mera naturalidade geográfica ou humana, sendo, na verdade, a expressão máxima de um segmento desse povo e de sua cultura.

Portanto, eram esses salões a expressão máxima dos cultos, festas e das manifestações de uma aristocracia que se tornava o ponto central da cosmologia escandinava, atribuindo à sua própria compreensão um caráter sagrado, político e até mesmo legislativo, pois davam a essas cidades e centros características de locais seguros, diferenciados e sociabilizados. Tal não acontecia nas zonas

23 HEDEAGER, op. Citi., 2011, p. 149-150.

"A criação dos locais sagrados na Escandinávia pré-cristã deve ter sido incorporada pela cosmologia nórdica, dos quais, no entanto, muito pouco se sabe. Em uma sociedade sem qualquer forma de poder publico central uma paz precária tinha de ser constantemente negociada. Aqui, as instituições mais importantes eram a casa, o salão e o thing, onde as negociações sociais e jurídicas ocorriam. De acordo com as sagas essas instituições eram os fundamentos sagrados da sociedade, os pontos focais na estrutura topográfica do universo islandês na Idade Média. Os locais mais comuns para o combate e 0 ataque se encontravam fora dos recintos das fazendas (utgard): na floresta, perto dos rios e em áreas limítrofes pertencentes ao mundo selvagem, isto é, o mundo perigoso de 'fora'." (Tradução livre do autor). 
fora das suas fronteiras, por serem regiões selvagens, de outras esferas espaciais e de outra compreensão social. Além da compreensão cósmica, não podemos nos esquecer de que eram tais salões e ritos também importantes na legitimação real. Locais e fatos que davam à realeza escandinava o papel principal de estabelecer a ordem e de possibilitar uma relativa paz, que gerasse e garantisse a sociabilidade e as condições para a execução das atividades religiosas, políticas, manufatureiras e comerciais desses povos.

Eram esses salões o coração dessas organizações sociais escandinavas, localizados nas áreas mais altas e de construção mais monumental do que os demais, cedendo às primeiras organizações urbanas e aos centros políticos e religiosos escandinavos uma compreensão cósmica que auxiliaria em suas formações. Sem as necessárias atribuições e compreensões de tais edifícios não podemos entender uma das principais características do período denominado viking, os centros políticos, religiosos e manufatureiros. Áreas nas quais os contatos com outros povos se tornou possível, contatos que possibilitaram o surgimento das fontes que estudamos em nossa contemporaneidade, possibilitando, assim, a troca de ideias, materiais e símbolos que tornariam a Escandinávia um local plural dentro de um tempo unificado, ao qual chamamos de período viking.

\section{Bibliografia}

\section{Fontes}

BREMEM, Adam of. Gesta Hammaburgensis Ecclesiae Pontificum. Tradução de F.J. Tschan. New York: Columbia University Press, 2002.

Leipzig, 1917.

Gesta Hammaburgensis Ecclesiae Pontificum. Ed. B. Schmeidler Hannover: Hannover and

OBRA ANÔNIMA. Beowulf. Tradução e edição de Howell D. Chickering, Jr. New York: Anchor Books, 2006.

OBRA ANÔNIMA. Edda poética. Tradução de Henry Adams Bellows. Disponível em: <http://www.sacred-texts.com/neu/poe/>. Acesso em: 08 ago. 2012.

OBRA ANONIMA. Grettis saga Ásmundarsonar. Tradução de Richard C. Halle Boer. Altnordische SagaBibliothek 8, 1900.

OBRA ANÔNIMA. Sagas islandesas Saga dos Volsungos. Tradução e edição de Théo de Borba Moosburger. São Paulo: Hedra, 2009.

OBRA ANÔNIMA. The Laxdoela Saga. Tradução de Margaret Arent. Washington: University of Washington Press, 1964. 
STURLUSON, Snorri. Ynglinga Saga. Tradução de Samuel Laing. Disponível em: <http://omacl.org/Heimskringla/ynglinga.html>. Acesso em: 08 ago. 2012.

. Hákonar Saga góda. In: Heimskringla. Tradução de N. Linder og H.A. Haggson. Disponível em: <http://www.heimskringla.no/wiki/Saga_Hákonar_góða>. Acesso em: 08 ago. 2012.

\section{Referências bibliográficas}

ABRAM, Christopher. Myths of the Pagan North. Auckland: Continuum International Publishing Group, 2011.

BRINK, Stefan. Naming the Land. In: The Viking World. (Org.) PRICE, Neil. New York: Routledge, 2007. p. 57-65.

CARDOSO, Ciro Flamarion. A interpretação da cosmogonia religiosa com a história entre os escandinavos. Rio de Janeiro: Revista Eletrônica de Antiguidade, n. 9, p. 8-19, 2012.

DAVIDSON, H.R. Ellis. The lost beliefs of Northern Europe. London: Routledge, 2003.

GRIFFITH, Paddy. Los Vikingos el terror de Europa. Tradução de Mateus Albert Sasot. Barcelona: Ariel, 2004.

HEDEAGER, Lotte. Iron Age Myth and Materiality: An Archaeology of Scandinavia ad 400-1000. New York: Routledge, 2011.

HERSCHEND, Frands. The idea of the Good in Late Iron Age Society. Uppsala: Uppsala Universitet, 1998.

The origin of the Hall in Southern Scandinavia. Tor, n. 25, p. 175-199, 1993.

HULTGARD, Anders. The religion of the Vikings. In: The Viking World. (Orgs.) BRINK, Stefan; PRICE, Neil. London: Routledge, 2007. p. 212-674.

HUTTON, Ronald. The pagan religions of the ancient British isles: their nature and legacy. Oxford (UK); Cambridge (Mass): Blackwell, 1995.

LINDOW, John. Norse mythology: a guide to the gods, heroes, rituals and beliefs. New York: Oxford University Press, 2002.

RAUDVERE, Catharina. Myth, genealogy, and narration: some motifs in Volsunga Saga from the perspective of the History of Religions. In: Reflections on Old Norse myths. (orgs.) HERMANN, Pernille; SCHJODT, Jens Peter; KRISTENSEN, Rasmus Tranum. Turnhout: Brepols Publishers n.v., 2007. p. 119-132.

RENAUD, Jean. Les dieux des Vikings. Rennes: Éditions Quest-France, 1996. 
RICHARDS, Julian D. Vikings. A very short introduction. New York: Oxford University Press, 2005.

ROESDAHL, Else. The Vikings. Tradução de Susan M. Margeson; Kirsten Williams. London: Penguin Books, 1998.

SAWYER, Peter. The Oxford illustrated History of the Vikings. New York: Oxford University Press, 2001.

SCHJODT, Jens Peter; KRISTENSEN, Rasmus Tranum. Reflections on Old Norse myths. Turnhout: Brepols Publishers n.v., 2007. p. 119-132.

SKRE, Dagfinn. The development of urbanism in Scandinavia. In: PRICE, Neil. (Org.). The Viking World. New York: Routledge, 2007. p. 83-92.

SLUPECKI, Leszek P. Pagan temple - Christian Church. The Problem of Old Norse Temples. In: Between Paganism and Christianity in the North. (Orgs.) SLUPECKI, Leszek P.; MORAWIEC, Jakub. RzesZów: Wydawnictwo Uniwersytetu Rzeszowskiego, 2009. p. 23-44.

STEINSLAND, Gro. Det hellige bryllup og norron kongeideologi. En analyse av hierogami-myten i Skírnismál, Ynglingatal, Háleygjatal og Hyndluljód. Oslo: Solum, 1991.

SUNDQVIST, Olof. An Arena for Higher Powers. Cult Buildings and Rulers in the Late Iron Age and The Early Medieval Period in The Mälar Region. In: Ideology and power in the Viking and Middle Ages Scandinavia, Iceland, Ireland, Orkney and the Faeroes. (Orgs.) STEINSLAND, Gro. Boston: Leiden, 2011. p. 163-210. 2002. Freyr's offspring: Rulers and religion in ancient Svea society. Uppsala: Uppsala Universitet, TODD, Malcolm. The early Germans. Oxford (UK); Cambridge (Mass): Blackwell, 1995.

ZACHRISSON, T. Gard, Gräns, Gravfält. Sammanhang kring ädelmetalldepaer och runstenar fran vikingetid och tidigmedeltid in Uppland och Gästrikland. Stockholm Studies in Archaeology, n. 15, p. 62134, 1998. 